\title{
Концептуализация журналистской профессии в контексте социологии
}

\author{
Павел Разин \\ Егор Жаровский
}

\begin{abstract}
В статье предпринята попытка определить возможность применения некоторых концептов социологической теории для изучения журналистской профессии. Авторы фокусируют внимание на двух социальных феноменах, которые присущи журналистскому сообществу, - иерархии статусов и социальной мобильности. На основании проведенного обзора теоретических исследований и анализа данных обосновывается необходимость расширения и обновления существующих в социологической науке положений, позволяющих охарактеризовать профессию журналиста и его работу в редакции СМИ.

Ключевые слова: журналистская профессия, журналист, социология, статусное неравенство, социальная мобильность.
\end{abstract}

\author{
(C) Разин Павел Владимирович \\ кандидат социологических наук, \\ доцент факультета журналистики \\ МГУ имени М.В.Ломоносова \\ (г. Москва, Россия), pavel380@gmail.com \\ (C) Жаровский Егор Романович \\ аспирант кафедры \\ социологии массовых коммуникаций \\ факультета журналистики \\ МГУ имени М.В.Ломоносова \\ (г. Москва, Россия), egor.heat@mail.ru
}

\section{Введение}

Множественные изменения, происходящие с журналистикой в настоящее время, заставляют исследователей СМИ регулярно обращаться к осмыслению данной профессии. Одни труды посвящены выживанию средств массовой информации и их работников в условиях мирового экономического кризиса (Якова, 2009; Виноградова, 2010). Другие работы фокусируются на технологических инновациях, меняющих повседневную работу журналиста (Кульчицкая, 2017; Каллиома, 2011). Отмечают ученые и влияние журналистской деятельности на общество, точнее на ту его часть, которая в отечественной и зарубежной литературе именуется аудиторией СМИ. Здесь, к примеру, затрагиваются вопросы формирования глобального информационного общества (Olausson, 2013), распространения массовой культуры (Sharkov, Potapchuk, 2018), воздействия на общественное мнение (McGregor, 2019), коммуникативного обслуживания и даже непосредственного участия журналистов в интеграции огромного количества сравнительно небольших сообществ наподобие групп в социальных сетях, субкультур, территориальных солидарностей и пр. (Разин, 2019).

Вместе с тем изучение журналистской профессии все чаще сводится либо к анализу прикладных аспектов работы в СМИ (Вырковский, Галкина, Колесниченко, Об- 
разцова, 2016), либо к составлению портрета журналистов на основе их мнений и предпочтений (Nygren, Dobek-Ostrowska (eds.), 2015). В результате сложнейшая система социальных отношений внутри и вне журналистского сообщества остается на периферии академической дискуссии.

Стоит отметить, что социологическая традиция в изучении журналистики сложилась достаточно давно и в настоящее время составляет одно из важнейших направлений современных медиаисследований. Общность журналистов может восприниматься здесь в качестве профессионального коммуникатора, передающего информацию своей аудитории, на что указывает И.Д. Фомичева (2012). Журналисты могут выступать и компетентными лицами при обсуждении социально значимых проблем. Так, рассуждая о роли журналистики в организации общественного диалога, А.И.Черных отмечает, что «социология и философия уже не представляют собой области, закрытые для журналистов. Последние все более втягиваются в гуманитарные исследования, предлагая свое видение тех или иных профессиональных проблем» (2010: 105).

Можно перечислить еще немало подобных представлений о журналистах. Однако они не могут в полной мере учесть и объяснить многообразие социальных отношений, в которые включена журналистская профессия. Для решения этой задачи необходимо обратиться к социологической науке. Представляется, что именно теоретические положения, существующие в социологии, позволят раскрыть предназначение журналистской профессии в социуме, а также обозначить место журналистов в системе общественных отношений.

\section{Социологические подходы к определению журналистики}

Приступая к рассмотрению вопроса о журналистах и журналистской профессии в контексте социологической теории как о предмете предпринимаемого нами исследования, необходимо определить концептуально-терминологические рамки понятия «профессия». Обращение к отечественным и зарубежным научным источникам указывает на разные трактовки этой категории. В российской социологической литературе под профессией может пониматься трудовая деятельность, нацеленная на получение дохода и требующая от человека применения на практике знаний, опыта и навыков, приобретенных в ходе обучения и работы1. В зарубежных же источниках можно обнаружить следующее определение: «профессия - форма наемного труда индивида, требующая от него вовлечения умственных способностей и технических навыков, дисциплины и стремления служить интересам общества»².

Несложно заметить, что профессия в рамках отечественной социологии подразумевает наличие у индивида специального образования и опыта работы, в то время как представители западной школы отводят ведущее место профессиональным качествам работника. Обе точки зрения представляются нам достаточно адекватными и точными при анализе журналистики как одной из профессий. Попытаемся теперь охарактеризовать профессию журналиста с помощью некоторых социологических воззрений на социальные процессы и явления.

С точки зрения структурного функционализма как одного из фундаментальных подходов в социологии любая деятельность человека может быть представлена в виде определенной функции в обществе. При этом последовательность действий, обеспечивающих эффективность функционирования социальной системы, со временем превращается в устойчивый образец поведения, воспроизводимый множеством индивидов, - паттерн (Parsons, 1991). В качестве такого паттерна можно рассматривать и журналистскую профессию, ко- 
торая предусматривает сбор, обработку и распространение циркулирующей в обществе информации.

Разрабатывая теорию символического интеракционизма, американский социолог Дж. Мид (1938) предполагал, что существование любой социальной системы обусловлено взаимодействием индивидов при помощи различных символов - слов или жестов. Журналист как непосредственный участник массовой коммуникации конструирует особую реальность, которая и состоит из предназначенных вниманию аудитории символов. В результате журналистская профессия представляет собой разновидность деятельности по созданию и передаче символов об окружающем мире, которые в конечном счете объединяют людей.

Еще один взгляд был выработан в рамках феноменологической социологии А. Шюцом (1970). Согласно ему, каждый индивид воспринимает окружающую действительность исходя из уникального набора жизненных ситуаций, сопряженных со становлением его личности, - обстоятельств рождения, воспитания, образования, принятия религиозных догм, влияния идеологий и культур. К отдельной категории познаваемых феноменов австрийский социолог относит объективный, по отношению к индивиду, опыт других людей, разделяющих с ним одну сферу деятельности. Соответственно, журналистская профессия может рассматриваться как фактор объединения людей со схожим видением мира.

Наконец, в последние десятилетия широкое распространение среди социологов получают представления, в которых акцентируется внимание на развитии общества в тесной взаимосвязи с информационно-коммуникационными технологиями. Из концепции социального пространства Г. Зиммеля и К. Уольффа (1950) в социологическом дискурсе возникает плеяда идей, затрагивающих проблемы влияния технологий на человека. Речь идет о различных вариантах теории сетевого общества (Castells, 1996; Hiltz, Turoff, 1993; van Dijk, 1999), фокусирующей внимание на погружении индивидов в единое коммуникативное пространство с сетевой структурой, вызванное процессами компьютеризации, виртуализации и цифровизации. Для журналистской профессии подобные изменения в первую очередь выражаются в усилении значимости социальных медиа в работе журналиста (Качкаева, Шомова (ред.), 2017), появлении новых специализаций (Балмаева, Лукина (ред.), 2016) и каналов распространения контента (Соколова, 2017) при работе в СМИ.

Своеобразным обобщением упомянутых выше подходов выступают представления о журналистике непосредственно в социологии СМИ. Размышляя о роли журналистской профессии в обществе, Е.П. Прохоров (2011) называет журналистику «наполнителем» информационного пространства и творчеством, предназначенным для массовой аудитории. И.Д. Фомичева (2012) говорит о СМИ как об особом виде социальных коммуникаций, направленном на численно большие, гетерогенные по составу, анонимные аудитории. В обоих случаях журналистская профессия выступает связующим звеном между огромным количеством людей.

Мы проанализировали основные подходы в социологии, с помощью которых можно прояснить сущность журналистской профессии в общественных отношениях. Каждый из них демонстрирует, что журналистика как профессия может быть успешно рассмотрена сквозь призму социологической теории. Интерпретации, полученные с помощью указанных выше подходов, позволяют по-новому взглянуть на профессию журналиста, концептуально обогащая уже существующие представления о ней и о ее предназначении в обществе.

Далее остановимся на двух аспектах статусном неравенстве и социальной мо- 
бильности журналистов. Они напрямую связаны с социальным статусом работников СМИ и, значит, помогут сделать обобщения социологического характера и о самой профессии журналиста.

\section{Статусное неравенство в журналистском сообществе}

Расслоение людей по признакам богатства, обладания властью, образованности, престижа занимаемого в обществе положения наблюдается в той или иной степени в рамках любого социума. Практически неизбежно расслоение фиксируется и внутри профессиональных общностей (сообществ ученых, учителей, врачей, военных, журналистов и др.). Очевидно, что и журналисты находятся в условиях статусного неравенства, поскольку каждый из них обладает разным уровнем образования, материальным достатком, разными рычагами влияния на других людей, занимаемой должностью, уважением со стороны коллег.

K настоящему времени в социологии выработано несколько подходов, объясняющих сущность неравенства и основанной на ней иерархии статусов. Все они могут быть применимы к общности журналистов. Согласно конфликтному подходу общество складывается из социальных отношений между людьми с разным положением в системе общественного производства. В «Манифесте коммунистической партии» К. Маркса и Ф. Энгельса эти люди объединены в противоборствующие друг с другом классы, имеющие неравные возможности при осуществлении труда, - буржуазию (правящий класс) и пролетариат (класс эксплуатируемых) ${ }^{3}$.

Применяя данный подход к современному журналистскому сообществу, можно обнаружить напряженность в отношениях рядовых журналистов с работодателями. В рамках международного исследовательского проекта Worlds of Journalism, реализованного в 2012-2016 гг., был проведен мас- штабный опрос журналистов из 67 стран $^{4}$. В частности, журналисты Султаната Оман (абсолютная монархия) в 60\% случаев заявили о чрезвычайно сильном давлении (ряде ограничений и завышенных требований к их работе) со стороны редколлегии и владельцев СМИ. В то же время 19,4\% британских журналистов, работающих в стране с конституционной монархией и, соответственно, в более демократичных условиях, дали аналогичную оценку их отношениям с начальством. Таким образом, разные условия труда объясняются неравенством статусов рядовых сотрудников СМИ и их работодателей, несмотря на принадлежность к одному профессиональному сообществу.

Альтернативный подход к обоснованию неравенства предлагает М. Вебер (1978). По мнению немецкого социолога, ключевой причиной социального неравенства в обществе является дефицит трех ресурсов, которыми стремятся обладать индивиды: богатства, власти и престижа. Исследования СМИ свидетельствуют, что от наличия у журналиста этих ресурсов во многом зависит его профессиональное самочувствие. Так, анализируя причины благоприятного отношения российских журналистов к собственной профессии, С. Пасти (2012) называет следующие факторы их удовлетворенности работой в СМИ: материальное благополучие, политическая независимость и возможность карьерного роста.

П.А. Сорокин (1962) считал, что неравенство в обществе представлено разнообразными формами, которые могут переплетаться друг с другом. Он выделял следующие разновидности статусного неравенства: политическое (положение индивида по отношению к институтам власти), экономическое (дифференциация людей по уровню дохода и благосостояния) и профессиональное (престиж рода деятельности индивида или занимаемой им внутри профессии позиции). 
Для журналистского сообщества все эти виды неравенства вполне актуальны. Результаты опроса, проведенного исследовательской группой ЦИРКОН в 2016 г., наглядно демонстрируют вариативность мнений российских журналистов касательно их отношения к действующим институтам власти, оплате труда в СМИ и престижности журналистской профессии 5 . В частности, 23\% опрошенных назвали свое материальное положение плохим, 54\% - средним и лишь 17\% оценили его как хорошее. Соответственно, российские журналисты обладают разным материальным благополучием, что закономерно приводит к возникновению статусного неравенства между ними по экономическим признакам (уровню дохода, владению имуществом, запасу денежных средств и т.п.).

Функциональная теория исходит из того, что любая разновидность труда, независимо от ее престижа, одинаково важна для общества, поскольку выполняет конкретную, необходимую ему функцию. Американские социологи К. Дэвис и У. Мур (1945) считают необходимым распределение индивидов по разным (не одинаково престижным) социальным позициям для поддержания устойчивости общества. В результате любая профессия, включая журналистику, имеет конкретное предназначение для общественной жизни. В то же время в зависимости от позиции в профессиональном сообществе журналисты по-разному воспринимают цель своей работы, о чем свидетельствует относительно недавний опрос американских журналистов (Willnat, Weaver, Wilhoit, 2019); рядовые работники прессы считают важным активное вмешательство СМИ в политическую повестку дня, а вот руководящий состав редакций (редакторы) выступает за сохранение статуса-кво в системе политических отношений.

Еще один подход к пониманию статусного неравенства был предложен французским социологом П. Бурдье (1991).
Одним из ключевых понятий его теории является габитус - система способов поведения, образов мышления и схем восприятия действительности, позволяющая индивиду адаптироваться к той или иной социальной среде. Применяя идеи Бурдье по отношению к журналистам, можно попытаться объяснить различия в восприятии журналистской профессии самими работниками СМИ. Так, результаты опроса 365 журналистов из 52 государств, проведенного немецким пиар-агентством Sweet Spot PR, показали, что журналисты из разных стран используют слова с разной коннотацией при выражении отношения к собственной профессии. В частности, скандинавские журналисты описывают свою работу при помощи слов «надежность», «качество» и «предвзятость», а сотрудники СМИ других европейских стран используют такие слова, как «независимость», «истина» и «борьба». Подобные различия могут быть обусловлены характеристиками понятия габитуса, основаннго на национальном менталитете и личном жизненном опыте журналиста.

\section{Социальная мобильность современного журналиста}

На протяжении жизни социальный статус (положение, занимаемое в обществе) любого индивида претерпевает изменения в зависимости от различных жизненных обстоятельств. Так, журналист может кардинально поменять сферу профессиональной деятельности (например, стать общественным деятелем или политиком), переехать в другую страну или выйти на пенсию. В таком случае речь идет о социальной мобильности журналиста, в результате чего меняется его положение в обществе. На сегодняшний день по поводу феномена социальной мобильности высказано немало концептуальных соображений. Некоторые из них могут оказаться весьма полезными для анализа журналистской профессии и работников СМИ. 
Так, П.А. Сорокин (1959) в работе «Социальная мобильность» приводит несколько оснований для классификации мобильности: с изменением или без изменения социального статуса индивида (горизонтальная и вертикальная мобильность); направление смены статуса (восходящая и нисходящая); сферы общественной жизни, в которых оказывается индивид (профессиональная, экономическая, политическая).

В силу разных социальных обстоятельств каждый из этих типов мобильности может найти свое проявление в журналистском сообществе. Например, рассуждая о методике управления персоналом газетных и телевизионных СМИ, К. Киллебрю (2002) считает создание благоприятного организационного климата (открытые и доверительные отношения между коллегами, обоснованная критика, регулярные стажировки работников) необходимым условием для предотвращения ухода журналиста из коллектива редакции. В сущности американский исследователь предлагает пути снижения мобильности работников СМИ внутри профессионального сообщества для сохранения устойчивости конкретного журналистского коллектива.

Одной из предпосылок социальной мобильности может выступать набор ценностей, основанный на идеалах рационализма и толерантности мышления, а также осознанном стремлении достичь жизненного успеха. По мнению П. Блау и О. Данкена (1967), именно эти ценности вместе с некоторыми характеристиками социального статуса родителей (их образованием, профессией, вероисповеданием, национальностью) предопределяют решения индивида по выбору сферы профессиональной деятельности. К примеру, опрос американских студентов показал, что личное стремление к самореализации и установка на улучшение мира (искоренение бедности, дискриминации и несправедливости) предопределили их выбор в пользу журналистской профессии (Coleman, Lee, Yaschur, Meader et. al., 2016). Измерение принятия решений, включающее в себя склонности, интересы, ценности, убеждения и идеалы индивида, оказывается настолько же важным в профессиональной самоидентификации и для российских студентов - будущих журналистов (Дорощук, 2013).

Социальная мобильность также рассматривается в контексте передачи статусов от предыдущего поколения к последующему. Французские исследователи Д. Берто и И. Берто-Вьям (1993) считают, что семья задает индивиду траекторию выбора профессии, стремясь сохранить сложившийся на протяжении нескольких поколений социальный статус семейной группы. Трансмиссия статуса от старших членов семьи к младшим происходит посредством устных рассказов о жизни или зафиксированных на бумажном (электронном) носителе воспоминаний (Томпсон, 2003).

Логично заключить, что и в журналистскую профессию люди могут приходить, опираясь на биографические сведения о других членах своей семейной группы. Результаты некоторых исследований подтверждают, что наряду со стремлением студента к творческой самореализации жизненный опыт родственников (родителей, дедушек, бабушек, братьев, сестер и др.) оказывает влияние на предрасположенность к творческой деятельности и профессиональные интересы учащихся, ориентируя их на выбор журналистской профессии (Franczyk, 2013; Ускова, 2011).

Социальная мобильность журналиста может быть обусловлена и экономическими причинами. Например, расширение набора вакансий в сфере услуг и появление рабочих мест, требующих от работников выполнения административно-управленческих функций, вследствие экономического роста приводит к интенсификации восходящей мобильности - увеличению количества индивидов, социальный статус 
которых повышается (Heath, 1981). Тем не менее изучение во второй половине 1980 гг. государств с активно развивающейся экономикой - Польши, Венгрии, Чехословакии, Швеции, Японии, Австралии - показало, что уровень вертикальной мобильности у жителей этих стран был невысоким (Erikson, Goldthorpe, 1992).

Десятилетия спустя подобная ситуация стала характерной уже для экономически развитых (постиндустриальных) стран в целом и отдельных профессиональных групп в частности. Журналисты не являются здесь исключением. Так, опрос 885 работников британских средств массовой информации продемонстрировал, что в 35\% случаев они не продвинулись по карьерной лестнице выше родителей.

\section{Заключение}

Проведенный анализ продемонстрировал довольно тесную связь между социологией и журналистской профессией. С одной стороны, социологическая теория дает возможность обозначить границы данного вопроса и лучше осмыслить контекст, в рамках которого можно рассматривать профессиональную деятельность журналиста. С другой - изучение работников СМИ может открыть социальные закономерности, осмысление которых будет развито уже в рамках самой социологии. Все это заставляет признать рассмотрение журналистской профессии с позиций социологической науки вполне перспективным.

Подводя итоги, можно сформулировать следующие выводы. Во-первых, существующие общие социологические теории вполне применимы к анализу журналистской профессии. Выдвинутые социологами XX в. теоретические положения до сих пор остаются актуальными, однако в силу их принципиально широкого взгляда на социальные процессы чрезвычайно плодотворной была бы разработка положений непосредственно для конкретных социальных практик, в частности журналистики, в современных условиях.

Во-вторых, проведенные на сегодняшний день эмпирические исследования в отношении журналистов и их профессиональной деятельности пока не позволяют подтвердить или опровергнуть положения социологических теорий, относящихся к журналистской профессии. В результате выявление связей между сложившейся на практике ситуацией и идеями, высказанными классиками социологической мысли, становится сложной задачей. По-прежнему актуален запрос на проведение эмпирических исследований журналистов с опорой именно на теоретико-концептуальный инструментарий социологии. Только они смогут обеспечить научную общественность достоверными сведениями об особенностях журналистской профессии в XXI в.

\section{Примечания}

${ }^{1}$ Социологический энциклопедический словарь / под ред. Г.В. Осипова. М.: НОРМА, 2000.

2 Bruce S., Yearley S. (eds.) (2006) The Sage Dictionary of Sociology. London: Sage Publishing.

${ }^{3}$ Маркс К., Энгельс Ф. Манифест коммунистической партии. Режим доступа: https:// www.marxists.org/russkij/marx/1848/manifesto.htm (дата обращения: 30.06.2019).

4 Исследовательский проект Worlds of Journalism. Режим доступа: https://www. worldsofjournalism.org (дата обращения: 30.06.2019). 
5 Результаты исследования «Представления журналистов о профессии и профессиональном сообществе». Режим доступа: http://www.zircon.ru/upload/iblock/bb5/ journalists_presentation.pdf (дата обращения: 30.06.2019).

6 Исследование журналистов «Будущее журналистики». Режим доступа: https:// sweetspotpr.com/future-of-journalism-usa/ (дата обращения: 30.06.2019).

7 Исследование «Работающие журналисты». Режим доступа: http://www.nctj.com/ downloadlibrary/JaW\%20Report\%202018.pdf (дата обращения: 30.06.2019).

\section{Библиография}

Берто Д., Берто-Вьям И. Семейное владение и семья: преемственность и социальная мобильность, прослеживаемые на пяти поколениях // Социологические исследования. 1993. № 2. С. 58-67.

Виноградова К.Е. Социальная ответственность деловых СМИ: опыт взаимодействия с властью и бизнесом в условиях экономического кризиса: автореф. дис. ... канд. полит. наук. СПб., 2010 .

Вырковский А.В., Галкина М.Ю., Колесниченко А.В., Образцова А.Ю. Жанровая структура работы журналиста // Вестн. ВГУ. Сер.: Филология. Журналистика. 2016. № 2. С. 86-92.

Дорощук Е.С. Система обеспечения профессиональной мобильности будущего журналиста: научное осмысление проблемы // Вестн. ЧГПУ им. И.Я. Яковлева. 2013. № 1 (77). Ч. 2. С. 44-50.

Каллиома Л.А. Журналист печатных СМИ в условиях цифровой революции: испытание переменами // Вестн. Моск. ун-та. Сер. 10: Журналистика. 2011. № 5. С. 102-106.

Кульчицкая Д.Ю. Социальные сети как инструмент в работе российского журналиста: результаты опроса // Вестн. Моск. ун-та. Сер.10: Журналистика. 2017. № 4. С.119-135.

Как новые медиа изменили журналистику. 2012-2016 / под науч. ред. С. Балмаевой, М. Лукиной. Екатеринбург: Гуманит. ун-т, 2016.

Мультимедийная журналистика / под общ. ред. А.Г .Качкаевой, С.А. Шомовой. М.: ГУ ВШЭ, 2017.

Пасти С. Современные российские журналисты: отношение к профессии // Вестн. Моск. ун-та. Сер.10: Журналистика. 2012. № 4. С. 22-41.

Прохоров Е.П. Введение в теорию журналистики. М.: Аспект Пресс, 2011.

Разин П.В. Субкультура и журналистика // Международная жизнь. 2019. Спец. вып. C. 42-44.

Соколова Д.В. Дистрибуция новостного контента в мессенджере Telegram // Медиаскоп. 2017. Вып. 4. Режим доступа: http://www.mediascope.ru/2380

Томпсон П. Голос прошлого. Устная история / пер. с англ. М.: Весь Мир, 2003.

Ускова Н.Н. Формирование мотивации на профессию «журналист» и развитие творческих способностей студентов // Сибирский педагогический журнал. 2011. № 10. C. 182-190.

Фомичева И.Д. СМИ среди видов социальной коммуникации // Вестн. Моск. ун-та. Сер. 10: Журналистика. 2012. № 1. С. 60-72.

Черных А.И. Журналистика и публичная экспертиза // Социологический журнал. 2010. № 4. С. 92-111.

Якова Т.С. Пресса Швейцарии в условиях мирового экономического кризиса // Вестн. Моск. ун-та. Сер. 10: Журналистика. 2009. № 6. С. 152-156. 
Blau P.M., Duncan O.D. (1967) The American Occupational Structure. New York: John Wiley\&Sons.

Bourdieu P. (1991) Language and Symbolic Power. Cambridge: Polity Press.

Castells M. (1996) The Rise of the Network Society. The Information Age: Economy, Society and Culture. Oxford: Blackwell Publishers.

Coleman R., Lee J.Y., Yaschur C., Meader A.P. et al. (2016) Why Be a Journalist? US Students' Motivations and Role Conceptions in the New Age of Journalism. Journalism 19 (6): 800-819. DOI: 10.1177/1464884916683554

Davis K., Moore W.E. (1945) Some Principles pf Stratification. American Sociological Review 10 (2): 242-249.

Erikson R., Goldthorpe J.H. (1992) The Constant Flux. A Study of Class Mobility in Industrial Societies. Oxford: University of Oxford.

Franczyk A. (2013) Choosing a Journalism Career among High School Students. International Journal of Pedagogy and Curriculum 19 (3): 223-227. DOI: 10.18848/2327-7963/CGP/ v19i03/58987

Heath A. (1981) Social Mobility (Fontana New Sociology). London: HarperCollins Distribution Services.

Hiltz S.R., Turoff M. (1993) The Network Nation: Human Communication via Computer. Cambridge: MIT Press.

Killebrew K.C. (2002) Culture, Creativity and Convergence: Managing Journalists in a Changing Information Workplace. The International Journal on Media Management 5 (1): 39-46.

McGregor S.C. (2019) Social Media as Public Opinion: How Journalists Use Social Media to Represent Public Opinion. Journalism 20 (8): 1070-1086. DOI: 10.1177/1464884919845458 Mead G.H. (1938) The Philosophy of the Act. Chicago: University of Chicago.

Nygren G., Dobek-Ostrowska B. (eds.) (2015) Journalism in Change. Journalistic Culture in Poland, Russia and Sweden. New York: Peter Lang.

Olausson U. (2013) Theorizing Global Media as Global Discourse. International Journal of Communication 7: 1281-1297.

Parsons T. (1991) The Social System. London: Routledge.

Schutz A. (1970) On Phenomenology and Social Relations. Chicago: University of Chicago. Sharkov F., Potapchuk V. (2018) Mass Culture and Mass Information within the Space of Modern. Communicology 6 (3): 153-163. DOI: 10.21453/2311-3065-2018-6-3-153-163 Sorokin P.A. (1959) Social and Cultural Mobility. New York: The Free Press.

Sorokin P.A. (1962) Society, Culture and Personality: Their Structure and Dynamics. New York: Cooper Square.

Simmel G., Wolff K.H. (1950) The Sociology of Georg Simmel. Glencoe, IL: Free Press. van Dijk J. (1999) The Network Society: Social Aspects of New Media. London: Sage Publishing. Weber M. (1978) Economy and Society. An outline of Interpretive Sociology. Los Angeles, CA: University of California Press.

Willnat L., Weaver D.H., Wilhoit C. (2017) The American Journalist in the Digital Age: How Journalists and the Public Think about Journalism in the United States. Journalism Studies 20 (3): 423-441. DOI: 10.1080/1461670X.2017.1387071 